\author{
Jan Acedański \\ Department of Economics \\ University of Economics in Katowice
}

\title{
Overlapping Generation Models with Heterogeneous Agents and Aggregate Uncertainty in Macroeconomic Modelling*
}

\begin{abstract}
The paper introduces the methodology of the overlapping generations models with heterogeneous agents and aggregate uncertainty - macroeconomic, stochastic general equilibrium models that account for consumer heterogeneity mainly with respect to age and wealth. Taking as an example my own model, which additionally allows for labour market status and skill heterogeneity, I show how consumer consumption and investment decision rules are derived. I also provide a detailed discussion of the most popular computational algorithms used to deal with those models. The model is then used to examine welfare gains from eliminating business cycle fluctuations on the labour market in Poland for different groups of consumers.
\end{abstract}

Keywords: DSGE models, overlapping generations, heterogeneous agents, business cycle, computational algorithms.

* The article was written for a project financed by a Polish National Science Centre grant based on decision DEC-2011/01/D/HS4/03430. 


\section{Introduction}

Dynamic stochastic general equilibrium models (DSGE) are a cornerstone of modern macroeconomic research methodology (Mankiw 2006, Blanchard 2008, Post Walrasian... 2006). Although they are still not very common in the Polish literature, they have been attracting increasing attention (Raport... 2009, Grabek, Kłos \& Koloch 2010, Wróbel-Rotter 2013). A characteristic feature of this class of models is their solid microfoundations as the key equations are derived from optimality conditions of microeconomic agents. For example, consumers choose consumption paths to maximise their expected lifetime utility and firms' investments are set to maximise the value of enterprises. It is also common practice to assume that agents hold rational expectations. DSGE models are not only utilized as a reliable macroeconomic policy analysis tool, but also for forecasting. Recent studies (Del Negro \& Schorfheide 2013, Kolasa, Rubaszek \& Skrzypczyński 2012) show that their forecast accuracy is already comparable to the accuracy of (B)VAR models and professional forecasters.

DSGE models are usually founded on the representative agent assumption, which states that all agents of the same type in the model are homogenous. In most cases, that significantly reduces the model's complexity without affecting its aggregate properties. However, if one wants to study distributional or lifecycle problems, for example, this assumption can no longer be used: heterogeneous agent models must be substituted. Moreover, some authors (Chang, Kim \& Schorfheide 2013) suggest that estimated parameters in the traditional DSGE models that do not take into account agents' heterogeneity may not be policy invariant, which makes them prone to the famous Lucas critique (1976). This is a particularly severe drawback, as the whole DSGE methodology is expected to refer to the policy-invariant, "deep" parameters only.

Formally, variable dynamics in DSGE models are implicitly described by a set of nonlinear stochastic difference equations. To obtain the explicit law of motions, one has to resort to complicated numerical procedures. Fortunately, MATLAB package Dynare offers a set of excellent tools that allow researchers to analyse many large-scale homogeneous agent DSGE models with little programming effort. This is one of the most important reasons for the widespread popularity of the homogeneous agents DSGE modelling.

As far as the models with heterogeneous agents are concerned, in most cases they cannot be analysed using Dynare. As a result, routines tailored to deal with the specific problem must be relied upon, which makes the modelling process considerably more demanding in terms of programming and computations. Additionally, the literature on the heterogeneous agent DSGE modelling is rather scarce, especially Poland's contribution (Rubaszek 2012, Brzoza-Brzezina et al. 
2013 are notable exceptions). I see that paucity as a serious obstacle to wider applications of this powerful analytical tool for studies on the Polish economy.

With this paper, I seek to begin to fill this gap. I present a heterogeneous agent DSGE model with aggregate uncertainty that accounts for both age and wealth heterogeneity among consumers. The model allows consumers to differ with respect to their labour market status as well as their skill level. I provide a detailed description of the model's building phases: derivation, numerical solution and simulation, then calibrate the parameters of the model to match basic stylised facts regarding labour market and macroeconomic aggregate dynamics in Poland. To illustrate the model's abilities I use it to assess the potential welfare gains from removing business cycle fluctuations for different groups of consumers. I can provide the MATLAB codes that replicate all the computations upon request.

Dynamic, stochastic economies with rational expectations and continuum of heterogeneous consumers with respect to wealth were first studied by M. Huggett (1993) and R. Aiyagari (1994). However, they considered the models without aggregate risk where all macroeconomic aggregates are constant in time. The models with aggregate fluctuations were computationally intractable until the concept of approximate aggregation was introduced by P. Krusell and A. A. Smith (1998). Their model was further extended to include other sources of consumer heterogeneity (see Krusell \& Smith 2006 for a review). The model presented in the paper, already used by J. Acedański (2014) to examine the welfare consequences of the recent pension reforms in Poland, is closely related to the work of K. Storesletten, C. I. Telmer and A. Yaron (2007), who also consider the model with wealth and skill heterogeneity as well as the overlapping generations. However, they focus on modelling individual income risk while I concentrate on labour market risk. The two models also differ in terms of asset structure.

The discussion of the welfare consequences of business cycle fluctuations was triggered by the seminal work of R. E. Lucas (1987), who argued that very little is gained from eliminating business cycles. A more detailed review of the copious literature on this topic was done by J. Acedański (2007), among others. Here I only point out that K. Storesletten, C. I. Telmer and A. Yaron (2001) used a simplified version of their abovementioned later model to examine the cost of the business cycle in the overlapping generation setup.

An excellent discussion of the computational tools used to analyse heterogeneous agent DSGE models can be found in a textbook written by B. Heer and A. Maussner (2009). Recent developments in this field are nicely compared and summarised by W. J. Den Haan, K. L. Judd and M. Juillard (2010) and W. J. Den Haan (2010). In my study, I use the algorithm proposed by L. Maliar, S. Maliar and F. Valli (2010). 
The rest of the paper is organised as follows. The equations for the model are derived in the next section while Section 3 describes the calibration of the model's parameters. Section 4 provides a discussion the computational algorithms. Finally, I present the results of my exercise.

\section{Model}

\subsection{General Framework}

The economy is populated by a continuum of finitely lived agents indexed by $i$ that differ in terms of age $a$, skill level $s$, employment status $\varepsilon$ and wealth $k$. For the sake of simplicity I omit the time subscripts and use primes to denote next periods. One period in the model corresponds to one year. The agents enter the market at the age of 20, work for 40 years, then retire and live, at most, up to the age of 99 . As a result, each cohort in the model lives for 80 years.

Young agents either work $(\varepsilon=1)$ or are unemployed $(\varepsilon=0)$. If employed, they supply $\xi_{s, a} l$ effective units of labour and get the pre-tax income $\xi_{s, a} l W$, where $W$ stands for the aggregate wage, $l$ is the constant for all agents' exogenous labour supply and $\xi_{s, a}$ denotes the efficiency factor. The unemployed agents collect unemployment benefits that are proportional to the mean wage in the economy $\theta_{u} \bar{\xi} l W$, where $\theta_{u}$ is the unemployment replacement rate and $\bar{\xi}$ denotes the mean labour efficiency across employed agents. Retirees receive pensions that are proportional to the wage of an employed agent of age $59 \theta_{r} \xi_{s, 59} l \mathrm{~W}$, where $\theta_{r}$ represents the pension replacement rate. Moreover, all agents collect interest from their wealth according to aggregate interest rate $R$. An agent $i$ 's work-related income $d$ is given by:

$$
d_{i}=(1-\tau) l W\left[\xi_{s, a} \cdot I\left(a_{i}<60, \varepsilon_{i}=1\right)+\theta_{u} \bar{\xi} \cdot I\left(a_{i}<60, \varepsilon_{i}=0\right)+\theta_{r} \xi_{s, 59} \cdot I\left(a_{i} \geq 60\right)\right],
$$

where $I$ stands for the indicator function and $\tau$ is the labour tax rate.

I assume that the agents who die leave their capital for the new-born agents that replace them, but do not take into account leaving the bequest when facing their consumption-investment problems as the bequest does not enter the agent's utility function. This assumption helps to keep the model closer to the data without making the agents' decision horizon infinite. Alternatively, one can assume that the wealth of dead agents is collected by the government and immediately spent on public consumption. Another possibility is to extend the agents utility function to account for the bequest amount (but not the utility from the bequest for future generations). That would motivate agents to lower their consumption and keep some wealth for a future generation. 
The production sector consists of one representative firm that hires capital and labour from agents and produces a single consumption good according to the standard Cobb-Douglas technology:

$$
Y=Z K^{\alpha} L^{1-\alpha}
$$

where $Z$ is the stochastic aggregate productivity shock and $K$ and $L$ are the aggregate capital and aggregate effective labour, respectively:

$$
K=\int k_{i} d i, \quad L=l \int \xi_{s, a} I\left(a_{i}<60, \varepsilon_{i}=1\right) d i .
$$

Note that both variables depend on the aggregate productivity shock. For the aggregate labour supply, this is the case because the fraction of the employed agents fluctuates with business cycles. Since the firm operates on the competitive market, it sets the aggregate wage and interest rate equal to the marginal products of labour and capital:

$$
W=(1-\alpha) Z K^{\alpha} L^{-\alpha}, \quad R=\alpha Z K^{\alpha-1} L^{1-\alpha} .
$$

The model also accounts for government, which imposes taxes on the income from work to finance the unemployment benefits and pensions. The tax rate is set so that the government budget is balanced for every period:

$$
\tau=\frac{\theta_{u} \bar{\xi} \int I\left(a_{i}<60, \varepsilon_{i}=0\right) d i+\theta_{r} \int \xi_{s, 59} I\left(a_{i} \geq 60\right) d i}{\int \xi_{s, a} \cdot I\left(a_{i}<60, \varepsilon_{i}=1\right) d i+\theta_{u} \bar{\xi} \int I\left(a_{i}<60, \varepsilon_{i}=0\right) d i+\theta_{r} \int \xi_{s, 59} I\left(a_{i} \geq 60\right) d i} .
$$

\subsection{The Decision Problem Agents Face}

In every period an agent of age a faces the following consumption-saving problem: given her capital stock $k$, the aggregate state of the economy $Z$ and the individual income $d$, she has to decide how much of her current wealth to consume and how much to save to maximise her expected lifetime utility. For clarity, the variables below are indexed by an agent's age. But still, the time subscripts are omitted.

The problem can be written as follows:

$$
\begin{gathered}
\max _{c_{a} k_{a+1}} E \sum_{h=0}^{99-a} \beta^{h} q_{a+h, a+h+1} U\left(c_{a+h}\right) \quad \text { s.t. } \\
k_{a+h+1}=\left(1-\delta+R_{a+h}\right) k_{a+h}+d_{a+h}-c_{a+h}, \\
k_{a+h+1} \geq \underline{k}, \quad h=0,1, \ldots, 99-a,
\end{gathered}
$$

where $E$ is the expectation operator, $\beta$ - the discount factor, $q_{a, a+1}-$ the survival probability from age $a$ to $a+1, \delta$ - the capital depreciation rate, $c$-individual consumption, $\underline{k}$ - debt limit, and 


$$
U(c)=\frac{c^{1-\gamma}-1}{1-\gamma}
$$

is the one-period utility function (referred to as the constant relative risk aversion - CRRA), with $\gamma$ denoting the risk aversion parameter.

It should be noted that there is a series of constraints (7) that describe the laws of motion for the individual capital - one for every period of an agent's remaining life. This is also the case for the debt limit conditions (8) that result from the borrowing constraints. However, for an agent at age a there are only two decision variables: current consumption $c_{a}$ and the next period capital stock $k_{a+1}$.

Due to the non-negativity constraints, the first-order optimality conditions that characterise an agent's decision rules are given by the Kuhn-Tucker theorem:

$$
\begin{gathered}
c_{a}^{-\gamma}-\lambda_{a}=\beta q_{a, a+1} E\left[c_{a+1}^{-\gamma}\left(1-\delta+R_{a+1}\right)\right], \\
k_{a+1}=\left(1-\delta+R_{a}\right) k_{a}+d_{a}-c_{a}, \\
k_{a+1} \geq \underline{k}, \quad \lambda_{a} \geq 0, \quad \lambda_{a}\left(k_{a+1}-\underline{k}\right)=0 .
\end{gathered}
$$

Here, $\lambda_{a}$ is the Lagrange multiplier associated with the borrowing constraint (8). If it is not binding, then $\lambda_{a}=0$. Equation (10) is the well-known intertemporal optimality condition. An agent should choose the consumption path so that the utility loss from one unit of the current consumption (1.h.s) equals the discounted expected utility gain from the higher consumption in the next period (r.h.s).

Plugging (11) into (10) to eliminate the current and the future consumption yields what is known as the Euler equation for the capital stock. It implicitly describes the sequence of optimal decision rules regarding the individual capital stock:

$$
k_{a+1}=\left(1-\delta+R_{a}\right) k_{a}+d_{a}-\left[\lambda_{a}+\beta q_{a, a+1} E\left(\frac{1-\delta+R_{a+1}}{\left[\left(1-\delta+R_{a+1}\right) k_{a+1}+d_{a+1}-k_{a+2}\right]^{\gamma}}\right)\right]^{-\frac{1}{\gamma}} .
$$

Together with budget constraint (11), this relationship implicitly determines an agent's optimal consumption-saving behaviour.

At this point it is worth mentioning that problem (6)-(9) can also be stated in an alternative form using dynamic programming notation and the Bellman optimality principle:

$$
\begin{gathered}
V(k, a, \varepsilon, s, K, Z)=\max _{c_{a, k_{a+1}}}\left\{U\left(c_{a}\right)+\beta q_{a, a+1} E\left[V\left(k^{\prime}, a+1, \varepsilon^{\prime}, s, K^{\prime}, Z^{\prime}\right) \mid \varepsilon, K, Z\right]\right\} \text { s.t. } \\
k_{a+1}=\left(1-\delta+R_{a}\right) k_{a}+d_{a}-c_{a}, \quad k_{a+1} \geq \underline{k} .
\end{gathered}
$$

The value function $\mathrm{V}$ for an agent of age a represents a maximal discounted expected utility from her current and future consumption: 


$$
V(k, a, \varepsilon, s, K, Z)=\max _{c_{a}, k_{a+1}}\left\{E \sum_{h=0}^{99-a} \beta^{h} q_{a+h, a+h+1} U\left(c_{a+h}\right)\right\} \text { s.t. (15). }
$$

It is possible to obtain exactly the same optimality conditions (10)-(12) from problem (14)-(15) using the first order conditions of the maximum on the r.h.s. of (14) as well as the envelope theorem that shows how to differentiate value function $V$.

\subsection{The Stochastic Structure of the Economy}

There are three stochastic shocks in the model. The aggregate productivity shock $Z$ is represented by a two-state Markov chain with the transition matrix $P_{Z}$. The states $Z=\left\{Z_{b}, Z_{g}\right\}$ represent the recession and expansion periods in the economy. The individual employment shock $\varepsilon$ is also modelled as a two-state Markov chain with the transition matrix $P_{\varepsilon}\left(Z, Z^{\prime}, s, a\right)$ that depends on the current and the future state of the economy as well as an agent's skill level and age. Finally, the lifetime in the model is stochastic. For every cohort $a$, there is a fraction $1-q_{a, a+1}$ of agents who die. It should also be noted that in my model I do not allow agents to change their skill level. However, this assumption can easily be relaxed.

\section{Calibration}

The baseline calibration is presented in Table 1 . The capital share of output $\alpha$ is set at 0.45 , which is close to the value observed in Poland. The values of the capital depreciation rate $\delta=0.055$ and the discount rate $\beta=0.98$ are calibrated jointly to match the interest rate of about $5 \%$ and the average share of investment in output, which is about $20 \%$ in Poland. I use the standard value for the coefficient of relative risk aversion $\gamma=2$. The compensation rates for agents who do not work equal $\theta_{u}=0.2$ and $\theta_{r}=0.6$. As far as the skill level is concerned, we have three groups of agents in the model: low-, medium- and high-skilled, which broadly correspond to people with a primary, secondary and tertiary education. This breaks down to $15 \%, 70 \%$ and $15 \%$ of the Polish population, respectively. Finally, the debt limit equals $75 \%$ of the wage in the model and varies across the skill levels.

The individual efficiency factors $\xi$ shown in Table 2 are calibrated to match the observed differences in wages according to the Structure of Earnings Survey conducted by Eurostat. The data show that the earnings of the low-skilled (primary-educated) workers are about $20 \%$ lower than those of the medium- 
-skilled (secondary-educated), while the high-skilled (tertiary-educated) earn about $65 \%$ more. Similarly, in Poland young people (20-29 years) earn about $20 \%$ lower wages than those in other age brackets. The differences for the other age groups are small, so we have left them out.

Table 1. Baseline Calibration of the Model

\begin{tabular}{|l|c|c|}
\hline \multicolumn{1}{|c|}{ Description } & Parameter & Value \\
\hline Capital share of output & $\alpha$ & 0.45 \\
\hline Capital depreciation rate & $\delta$ & 0.055 \\
\hline Discount rate & $\beta$ & 0.98 \\
\hline Risk aversion & $\gamma$ & 2 \\
\hline Net unemployment benefit rate & $\theta_{u}$ & 0.2 \\
\hline Net pension replacement rate & $\theta_{r}$ & 0.6 \\
\hline Share of low-, medium- and high-skilled workers & $\omega$ & $\{0.15 ; 0.7 ; 0.15\}$ \\
\hline Individual labour supply & $l$ & 1 \\
\hline Debt limit & $\underline{k}$ & $-0.75(1-\tau) l W \xi_{s}$ \\
\hline
\end{tabular}

Source: the author's calculations.

Table 2. Calibration of the Individual Labour Efficiency Factors

\begin{tabular}{|c|c|c|c|c|c|c|}
\hline \multirow{2}{*}{ Parameter } & \multicolumn{3}{|c|}{ Skill level } & \multirow{2}{*}{ Parameter } & \multicolumn{2}{|c|}{ Age } \\
\cline { 2 - 4 } \cline { 6 - 7 } & low & medium & high & & $20-29$ & $30-59$ \\
\hline$\xi_{s}$ & 0.8 & 1 & 1.65 & $\xi_{a}$ & 0.8 & 1 \\
\hline
\end{tabular}

Source: the author's calculations.

To calibrate the Markov chain for aggregate productivity I calculate logdeviations from the HP-filtered trend of yearly data on Polish GDP covering the period 1996-2013. This implies a symmetric business cycle where each phase lasts 3.75 years on average and productivity shock values of $Z_{b}=0.986$ during the recessions and $Z_{g}=1.014$ for periods of growth. The transition probabilities $P_{\varepsilon}$ are calibrated to match the average level $\bar{u}$ and the duration $u_{l}$ of the unemployment in Poland during booms and recession for workers of different skill levels and age based on the data from the Labour Force Survey. Since the data on the mean level of unemployment are grouped into 5-year bins, the values for each age were linearly interpolated. According to the data on the length of unemployment, I also assume that it is equal for all education levels and distinguish only two age groups: 20-39 and 40-59. Based on these data, I calculate the transition probabilities in the following way. The probability of staying unemployed is: 


$$
p_{u u}(a, Z)=1-u_{l}^{-1}(a, Z)
$$

while the probability of losing a job is:

$$
p_{e u}(a, s, Z)=\left[\bar{u}\left(a+1, s, Z^{\prime}\right)-\bar{u}(a, s, Z) \cdot\left(1-p_{u u}(a, Z)\right)\right] \cdot[1-\bar{u}(a, s, Z)]^{-1},
$$

where $\bar{u}(a, s, Z)$ denotes the mean unemployment rate for a worker of age $a$ and skill level $s$ when the state of the economy is $Z$. Finally, the survival rates $q(a, a+1)$ are taken from Polish unisex lifetables from the year 2012.

\section{Computational Algorithms}

\subsection{General Outline of the Computational Procedure}

The dynamics of individual capital and consumption evolve according to equations (13) and (11). Below, I describe how to compute the explicit decision rules of the form:

$$
k_{a+1} \equiv k_{a+1}(k, a, \varepsilon, s, K, Z) \quad \text { and } \quad c_{a} \equiv c_{a}(k, a, \varepsilon, s, K, Z) .
$$

My algorithm uses three important concepts. First, a backward iteration is employed to exploit the finite lifetime of agents and the recursive nature of their decision problem. Then, the Euler equation iteration algorithm proposed by L. Maliar, S. Maliar and F. Valli (2010) is used to find the explicit decision rules of agents from a given cohort, followed by the approximate aggregation property discussed by P. Krusell and A. A. Smith (1998). Their algorithm iterates on the first two concepts to find the law of motion for the aggregate capital that fulfils the rational expectation requirements. I start the discussion looking at the third algorithm and then move to the previous ones.

\subsection{Krusell and Smith Algorithm}

From (13), it is clear that the optimal level of the next period capital $k^{\prime}$ depends on the expected aggregate interest rate in the next period $R$ ', among other things. This, in turn, is related to the mean level of the aggregate capital $K^{\prime}$, which is determined by decisions taken by every individual. As a result, a fully rational agent should take into account the decisions of all other agents in the model. Eventually, to make fully rational decisions, an agent should track the whole distribution of the wealth across agents, which is an infinite dimensional object. However, this assumption seems as unrealistic as it is computationally infeasible. P. Krusell and A. A. Smith showed that it can be sufficient to take into account only the first few moments of the capital distribution to predict the next period's 
mean aggregate capital accurately. In fact, my model assumes that agents use the autoregressive law of motion for forecasting the mean level of the aggregate capital:

$$
K^{\prime}=b_{0 b}+b_{1 b} K \quad \text { if } \quad Z=Z_{b}, \quad K^{\prime}=b_{0 g}+b_{1 g} K \quad \text { if } \quad Z=Z_{g} .
$$

This is precisely the reason for including $\mathrm{K}$ as the argument of the decision rules (19) as well as the value function (14). The coefficients $b=\left[b_{0 b}, b_{1 b}, b_{0 g}, \mathrm{~b}_{1 g}\right]$ are set to achieve the highest possible consistency between the perceived laws of motion (20) and the actual dynamics of the mean aggregate capital in the model. To sum up, the iterative algorithm proceeds as follows:

1. Set initial values of the coefficients $b^{(0)}$.

2. For the given $b^{(j)}$, find the individual's decision rules $c_{a}=c_{a}(k, a, \varepsilon, s, K, Z)$ and $k_{a+1}=k_{a+1}(k, a, \varepsilon, s, K, Z)$ that solve the individual's consumption-saving problem (6)-(8) for all cohorts $a$.

3. Given the decision rules, simulate the model for $T$ periods and compute a time path for the mean aggregate capital.

4. Estimate the new autoregressive coefficients $b^{(j+1)}$ using ordinary least squares.

5. If $\left\|b^{(j+1)}-b^{(j)}\right\|<v_{b}$ then stop; otherwise update vector $b^{(j+1)}=\eta_{b} b^{(j+1)}+$ $+\left(1-\eta_{b}\right) b^{(j)}$ and return to step 2 .

\subsection{Solving the Individual Decision Problem with Backward Iteration and Euler Equation Iteration}

As far as step 2 is concerned, the backward iteration method is used. Because agents do not derive utility from leaving bequests, the optimal decisions for 99-year-old agents are:

$$
k_{100}(k, a, \varepsilon, s, K, Z)=0 \quad \text { and } \quad c_{99}(k, a, \varepsilon, s, K, Z)=k_{99}+d_{99} .
$$

To find the decision rules for younger agents, I follow L. Maliar, S. Maliar and F. Valli (2010) and discretise the state space for the individual and the aggregate capital and look for the optimal next period's capital by iterating the Euler equation (13). More precisely, with some initial decision rule $k_{a+1}^{(0)}$ and coefficients, $b^{(j)}$ the r.h.s. of (13) is calculated on the predefined grid and used to update the decision rule. It is them iterated until convergence. To calculate the expectation term, the transition probabilities are used as well as the decision rule of the next cohort (for $k_{a+2}$ term). This part of the solution procedure can be summarised as follows:

2.1. Compute the decision rules for the last generation given by (21).

2.2. For agents of age $a=99-s$ : 
2.2.1. Set the initial policy $k_{a+1}^{(0)}=k_{a+2}$, where $k_{a+2}$ is taken from the next cohort policy.

2.2.2. Set $\lambda_{a}=0$. Compute the new policy function $k_{a+1}^{(i+1)}$ on the predefined grid from the r.h.s. of (13). The expectation term is based on the transition probabilities $P_{Z}$ and $P_{\varepsilon}$. The next period interest rate $R_{a+1}$ is computed using the coefficients $b^{(j)}$ for the mean aggregate capital perceived laws of motion.

2.2.3. If some elements of $k_{a+1}^{(i+1)}$ lay outside the capital grid domain, set them to the boundary values.

2.2.4. Update the policy function $k_{a+1}^{(i+1)}=\eta_{k} k_{a+1}^{(i+1)}+\left(1-\eta_{k}\right) k_{a+1}^{(i)}$.

2.2.5. If $\left\|k_{a+1}^{(i+1)}-k_{a+1}^{(i)}\right\|<v_{k}$, then move to step 2.2.6; otherwise return to step 2.2.2.

2.2.6. Compute the optimal consumption policy from the budget constraint (15).

2.3. Repeat step 2.2. for all $s=1,2, \ldots, 79$.

\subsection{Simulating the Model}

Step 3 simulates the model. Here, I do not perform full Monte Carlo simulations with some predefined number of agents but instead follow B. Heer and A. Maussner $(2009$, p. 541-545) and simulate only the aggregate productivity shock. Then, for every period, the individual capital density functions are analytically computed for each skill level and age by taking advantage of the fact that the discretised individual capital level dynamics are described by a Markov chain with transition probabilities depending on the current and the future state of the economy.

To be more specific, let $k^{i}$ denote $i$-th point on the individual capital grid and define the following probabilities:

$p_{k}^{(i, j)}(a, \varepsilon, s, K, Z)$ is the probability that an agent of age $a$, employment status $\varepsilon$, skill level $s$ changes their capital stock from $k^{i}$ to $k^{j}, i, j \in\left\{1,2, \ldots, n_{k}\right\}$,

$p_{Z}^{(i, j)}$ is the probability that the aggregate state of the economy switches from $Z_{i}$ to $Z_{i}, i, j \in\{b, g\}$;

$p_{\varepsilon}^{(i, j)}\left(a, s, Z, Z^{\prime}\right)$ is the probability that the employment status of an agent moves from $i$ to $j, i, j \in\{0,1\}$.

If $k^{j} \leq k_{a+1}\left(k^{i}, a, \varepsilon, s, K, Z\right) \leq k^{j+1}$, then $p_{k}^{(i, j)}(a, \varepsilon, s, K, Z)=\frac{k_{a+1}\left(k^{i}, a, \varepsilon, s, K, Z\right)-k^{j}}{k^{j+1}-k^{j}}$ and $p_{k}^{(i, j+1)}(a, \varepsilon, s, K, Z)=1-p_{k}^{(i, j)}(a, \varepsilon, s, K, Z)$. The probabilities $p_{\varepsilon}^{(i, j)}\left(a, s, Z, Z^{\prime}\right)$ and $p_{Z}^{(i, j)}$ are taken from the matrices $P_{\varepsilon}$ and $P_{Z}$.

For a given mean aggregate capital $K$, the evolution of an agent's capital stock can be described by the multi-dimensional Markov chain with states $G(k, a, \varepsilon, s, Z)$. The probabilities of moving from $g\left(k^{i k}, a, \varepsilon^{i \varepsilon}, s, Z^{i Z}\right)$ to $g\left(k^{j k}, a+1, \varepsilon^{j \varepsilon}, s, Z^{j Z}\right)$ are given 
by $p_{k}^{(i k, j k)}\left(a, \varepsilon^{i \varepsilon}, s, K, Z^{i Z}\right) \cdot q_{a, a+1} \cdot p_{Z}^{(i Z, j Z)} \cdot p_{\varepsilon}^{(i \varepsilon, j \varepsilon)}\left(a, s, Z^{i Z}, Z^{j Z}\right)$. For agents who die, the transition probabilities from $g\left(k^{i k}, a, \varepsilon^{i \varepsilon}, s, Z^{i Z}\right)$ to $g\left(k^{i k}, 20,0, s, Z^{j Z}\right)$ (new-born unemployed agents) equal $\left(1-q_{a, a+1}\right) \cdot \bar{u}\left(20, s, Z^{j Z}\right) \cdot p_{Z}^{(i Z, j Z)} \cdot p_{\varepsilon}^{(i \varepsilon, j \varepsilon)}\left(a, s, Z^{i Z}, Z^{j Z}\right)$ and to $g\left(k^{i k}, 20,1, s, Z^{j Z}\right)$ (new-born employed agents) the probabilities are given by $\left(1-q_{a, a+1}\right) \cdot\left(1-\bar{u}\left(1, s, Z^{j Z}\right)\right) \cdot p_{Z}^{(i Z, j Z)} \cdot p_{\varepsilon}^{(i \varepsilon, j \varepsilon)}\left(a, s, Z^{i Z}, Z^{j Z}\right)$, where $\bar{u}\left(20, s, Z^{j Z}\right)$ denotes the mean unemployment rate for 20 -year-old agents when the aggregate state of the economy is $Z^{j Z}$. All other transition probabilities are 0 . Note that transitions between the skill level $s$ are not allowed.

This multi-dimensional chain can easily be transformed to a one-dimensional chain with $n_{k} \cdot 80 \cdot 2 \cdot 3 \cdot 2$ states, where $n_{s}$ represents the number of different skill levels, and the transition matrix $P(K)$. If $\Pi_{0}$ denotes the initial distribution of the capital across all agents, than the distribution in period $t$ is simply given by:

$$
\Pi_{t}=\Pi_{0} \prod_{i=1}^{t} P\left(K_{i-1}\right) \text {. }
$$

\subsection{Parametrisation}

For the individual capital holdings the decision rule is approximated on the interval $[k ; 50]$ with 150 grid points. Following L. Maliar, S. Maliar and F. Valli (2010), a polynomially spaced grid of $7^{\text {th }}$ order is used; it is much denser near the borrowing constraint where the decision rule is far from linear. For the aggregate capital a uniformly spaced 10-point grid in interval $[5.9 ; 7.2]$ is used. The law of motion for the aggregate capital for $T=4000$ periods is simulated. In this step, equispaced interval for the individual capital stock with 300 grid points is employed. The updating parameters equal: $\eta_{b}=0.5$ and $\eta_{k}=0.5$.

The capital distribution Markov chain has 216000 states. Therefore, the transition matrix $P(K)$ has about $5 \cdot 10^{10}$ entries. However, it can easily be handled as a sparse matrix as the vast majority of its entries are zeros.

\section{Application - the Welfare Cost of Business Cycles in Poland}

\subsection{Calculating the Cost}

To study the welfare cost of business cycles in Poland, two versions of the economy are considered: with the aggregate fluctuations (economy A), and without (economy B). The first one coincides exactly with the model described in previous sections. The second corresponds to the model where $Z=1$ and the labour market transition probabilities are constant in time. Following J.-O. Hairault, F. Langot and S. Osotimehin (2010) and also M. Reiter (2012), we set the labour market transition matrices in the economy without business 
cycles as the equally-weighted average of the transition matrices for booms and recessions in the economy with the aggregate fluctuations. However, the differences across age and skill level are still taken into account. A more detailed description of the methodology can be found in (Acedański 2015).

To assess the welfare gain from eliminating business cycles, I compare utilities from consumption in the two economies. Two measures of the gain are considered: the expected lifetime gain for new-born agents and a one-period or a momentary gain for agents of a given age. Following R. E. Lucas (1987), the welfare gain is defined as an average percentage increase in individuals' consumption in economy B needed to achieve the same utility level as in economy A. The gains are measured for every period of the transition from economy A to economy $\mathrm{B}$. The average lifetime gain $\lambda_{t}$ for a given period $t$ of the transition is calculated as follows:

$$
\lambda_{t}=100 \cdot\left[\left(\frac{E\left(V_{t}^{(A)}\left(k, 20, \varepsilon, s, H_{t}(K)\right)\right)}{E\left(V^{(B)}(k, 20, \varepsilon, s, K, Z)\right)}\right)^{\frac{1}{1-\gamma}}-1\right],
$$

where $V_{t}^{(A)}$ and $V^{(B)}$ denotes the value functions in period $t$ of the transition for economy A and for economy B, respectively, while $H_{t}(K)$ represents the law of motion for the aggregate capital on the transition path. Function $H$ returns the aggregate capital level in period $t$ of the transition, given the aggregate capital level $K$ at the beginning of the transition. It takes the same autoregressive form as in (20), but without distinguishing good and bad periods. Similarly, its parameters are set using an appropriately modified version of the Krusell-Smith procedure. The expectations in (23) are calculated across all arguments of the value functions excluding age.

The one-period gain $\lambda_{a, t}$ for a cohort $a$ is calculated in an analogous manner:

$$
\lambda_{a, t}=100 \cdot\left[\left(\frac{E\left(U\left[c_{a, t}^{(A)}\left(k, a, \varepsilon, s, H_{t}(K)\right)\right]\right)}{E\left(U\left[c_{a}^{(B)}(k, a, \varepsilon, s, K, Z)\right]\right)}\right)^{\frac{1}{1-\gamma}}-1\right] .
$$

Now, instead of the expected value function, expected one-period utilities are compared. The expectations in (24) are calculated across all arguments of the consumption policy functions excluding age. To integrate over the aggregate capital $K$, I build a discrete density function for $K$ based on a simulated long time series of the aggregate capital from economy B.

In other words, the one-period gain measures the difference in consumption for a given cohort between economies $\mathrm{A}$ and $\mathrm{B}$. The lifetime gain equals, approximately, the expected, discounted one-period gains. The results reported below are calculated as averages across all transition periods. 


\subsection{Results}

Table 3 provides the average lifetime gains for agents with different skill levels and initial employment status. We can see that an average new-born agent would pay $0.127 \%$ of her annual consumption every year to switch from economy A to economy B. The gain is lower for the low-skilled agents $(0.094 \%)$ and slightly higher for the medium-skilled $(0.135 \%)$ and the high-skilled $(0.136 \%)$ ones. The differences are caused by the constant unemployment benefits that, relatively, are much higher for the low-skilled agents. From the Table 3 we can also see that the gains are moderately higher for agents who enter the labour market as unemployed.

Table 3. Average Lifetime Gains (\% of lifetime consumption) for Agents with a Different Skill Level and Initial Employment Status

\begin{tabular}{|l|c|c|c|c|}
\hline \multicolumn{1}{|c|}{ Specification } & All & Low-skilled & Medium-skilled & High-skilled \\
\hline All & 0.127 & 0.094 & 0.135 & 0.136 \\
\hline Unemployed & 0.136 & 0.102 & 0.143 & 0.151 \\
\hline Employed & 0.117 & 0.091 & 0.125 & 0.116 \\
\hline
\end{tabular}

Source: the author's calculations.

Figure 1 shows the age profiles of the one-period gains. Clearly, the gains are much higher for the young agents. For example, annual consumption of an average 20 -year-old agent, measured in utility terms, is about $0.3 \%$ lower due to business cycles. For the high-skilled agent, the figure even exceeds $0.4 \%$. For agents 35 years old and above, the one-period gains stabilise below $0.1 \%$.

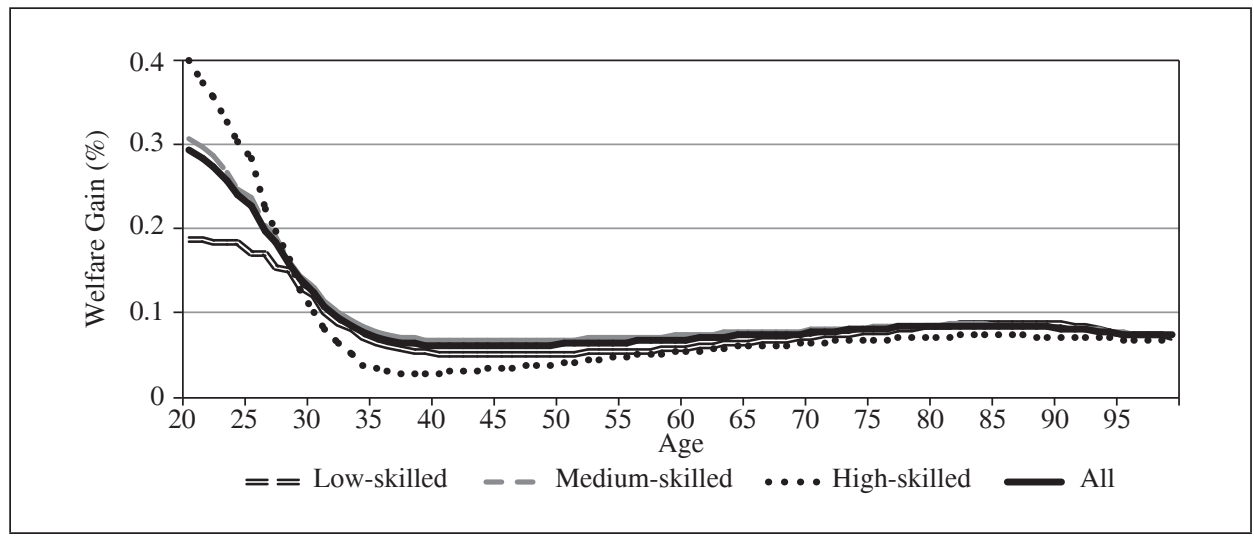

Fig. 1. One-period Gains for Cohorts and Skill Groups for the Baseline Calibration Source: the author's own calculations. 
Below, I additionally report the results for the model with the higher risk aversion $\gamma=4$. Here the gains are doubled. The average lifetime gain equals $0.273 \%$ of the lifetime consumption and the gain for the high-skilled agents exceeds $0.5 \%$. There are also significant differences in the lifetime gains between the mediumand the high-skilled agents, which was not the case under the baseline calibration.

Table 4. Average Lifetime Gains for Agents with a Different Skill Level and Initial Employment Status for the Higher Risk Aversion $\gamma=4$

\begin{tabular}{|l|c|c|c|c|}
\hline \multicolumn{1}{|c|}{ Specification } & All & Low-skilled & Medium-skilled & High-skilled \\
\hline All & 0.273 & 0.199 & 0.302 & 0.503 \\
\hline Unemployed & 0.296 & 0.211 & 0.323 & 0.579 \\
\hline Employed & 0.215 & 0.169 & 0.234 & 0.338 \\
\hline
\end{tabular}

Source: the author's calculations.

Figure 2 depicts the one-period gains' distribution across cohorts. As in the previous case, the young agents benefit the most from eliminating business cycles. The gain for the average new-born agent is close to $0.5 \%$, while for the high-skilled one the figure reaches almost $0.9 \%$. Interestingly, the one-period gains for 40-60-year-olds are negative, which means that these cohorts would be worse if business cycles were eliminated.

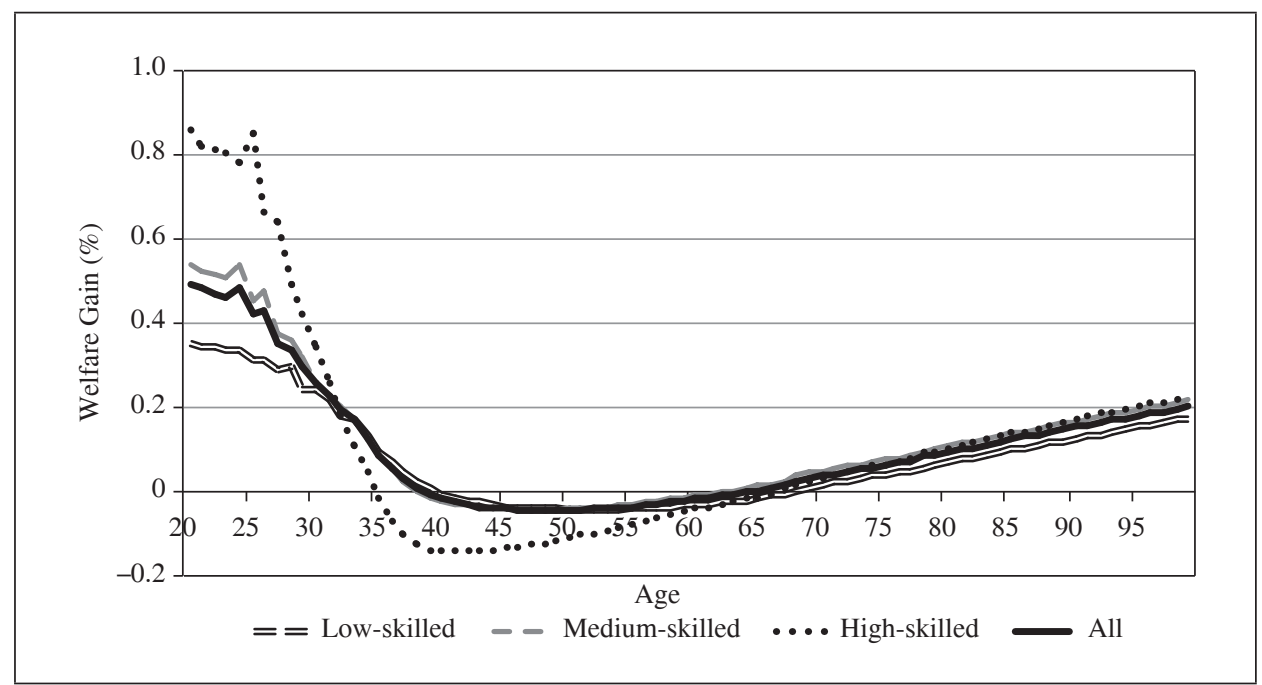

Fig. 2. One-period Gains for Cohorts and Skill Groups under the Higher Risk Aversion Source: the author's own calculations. 


\section{Conclusion}

In this paper I have focused on the methodology of the overlapping generation, heterogeneous agent DSGE model with aggregate risk. Using an exemplary model, I discuss the key steps of the model building procedure and provide a detailed discussion of the most popular computational algorithms used to deal with those models. Together with the codes I have provided and the literature listed in the paper, this description should allow interested researchers to conduct their own studies using this methodology.

The paper also illustrates that for the moderate cost of programming efforts, one receives a powerful tool for studying important macroeconomic problems involving various forms of consumer heterogeneity, which, as my empirical study documents, does matter as far as the gains from eliminating business cycles are concerned. I show that in Poland the gains are much higher for young and high-skilled consumers.

Finally, the popularity of the analysed models will obviously hinge on the availability of user-friendly, reliable and fast computational tools. Therefore, as computational technology and algorithms improve, we should definitely see increased interest and applications of the methodology I have discussed.

\section{Bibliography}

Acedański J. (2007), Metody szacowania kosztów wahań koniunkturalnych, "Zeszyty Naukowe Akademii Ekonomicznej w Katowicach. Studia Ekonomiczne", 46.

Acedański J. (2014), Pension Reforms and Welfare Gains from Eliminating Business Cycle in Poland (in:) J. Talasova, J. Stoklasa, T. Talasek (eds), Proceedings of $32^{\text {nd }}$ International Conference Mathematical Methods in Economics, Palacky University, Olomouc.

Acedański J. (2015), Youth Unemployment and Welfare Gains from Eliminating Business Cycle - The Case of Poland, manuscript.

Aiyagari S. R. (1994), Uninsured Idiosyncratic Risk and Aggregate Saving, "Quarterly Journal of Economics", 109(3), http://dx.doi.org/10.2307/2118417.

Blanchard O. (2009), The State of Macro, "Annual Review of Economics", 1(1), http:// dx.doi.org/10.1146/annurev.economics.050708.142952.

Brzoza-Brzezina M., Kolasa M., Koloch G., Makarski K., Rubaszek M. (2013), Monetary Policy in Non-representative Agent Economy: A Survey, "Journal of Economic Surveys", 27(4), http://dx.doi.org/10.1111/j.1467-6419.2011.00710.x.

Chang Y., Kim S. B., Schorfheide F. (2013), Labor-market Heterogeneity, Aggregation and Policy (In)variance of DSGE Model Parameters, "Journal of the European Economic Association", 11(S1), http://dx.doi.org/10.1111/j.1542-4774.2012.01098.x.

Del Negro M., Schorfheide F. (2013), DSGE Model-based Forecasting (in:) G. Elliott, A. Timmermann (eds), Handbook of Economic Forecasting, vol. 2, Elsevier, Amsterdam. 
Den Haan W. J., Judd K. L., Juillard M. (2010), Computational Suite of Models with Heterogeneous Agents: Incomplete Markets and Aggregate Uncertainty, "Journal of Economic Dynamics and Control", 34(1), http://dx.doi.org/10.1016/j.jedc.2009.07.001.

Den Haan W. J. (2010), Comparison of Solutions to the Incomplete Markets Model with Aggregate Uncertainty, "Journal of Economic Dynamics and Control", 34(1), http:// dx.doi.org/10.1016/j.jedc.2008.12.010.

Grabek G., Kłos B., Koloch G. (2010), SOE PL 2009 - Model DSGE małej otwartej gospodarki estymowany na polskich danych, "Materiały i Studia", no. 251, NBP, Warszawa.

Hairault J.-O., Langot F., Osotimehin S. (2010), Matching Frictions, Unemployment Dynamics and the Cost of Business Cycles, "Review of Economic Dynamics", 13(4), http://dx.doi.org/10.1016/j.red.2010.05.001.

Heer B., Maussner A. (2009), Dynamic General Equilibrium Modeling. Computational Methods and Applications, $2^{\text {nd }}$ ed., Springer, Berlin-Heidelberg.

Huggett M. (1993), The Risk-free Rate in Heterogeneous-agent Incomplete-insurance Economies, "Journal of Economic Dynamics and Control", 17(5-6), http://dx.doi. org/10.1016/0165-1889(93)90024-m.

Kolasa M., Rubaszek M., Skrzypczyński P. (2012), Putting the New Keynesian DGSE Model to the Real-time Forecasting Test, "Journal of Money, Credit and Banking", 44(7), http://dx.doi.org/10.1111/j.1538-4616.2012.00533.x.

Krusell P., Smith A. A. (1998), Income and Wealth Heterogeneity in the Macroeconomy, "Journal of Political Economy", 106(5), http://dx.doi.org/10.1086/250034.

Krusell P., Smith A. A. (2006), Quantitative Macroeconomic Models with Heterogeneous Agents (in:) R. Blundell, W. Newey, T. Pearson (eds), Advances in Economic and Econometrics: Theory and Applications, Ninth World Congress, Cambridge University Press, Cambridge.

Lucas R. E. (1976), Econometric Policy Evaluation: A Critique, "Carnegie-Rochester Conference Series on Public Policy", 1, http://dx.doi.org/10.1016/s01672231(76)80003-6.

Lucas R. E. (1987), Models of Business Cycles, Basil Blackwell, Oxford.

Maliar L., Maliar S., Valli F. (2010), Solving the Incomplete Markets Model with Aggregate Uncertainty Using the Krusell-Smith Algorithm, "Journal of Economic Dynamics and Control”, 34(1), http://dx.doi.org/10.1016/j.jedc.2009.03.009.

Mankiw G. N. (2006), Macroeconomists as Scientist and Engineer, "Journal of Economic Perspectives", 20(4), http://dx.doi.org/10.1257/jep.20.4.29.

Post Walrasian Macroeconomics. Beyond the Dynamic Stochastic General Equilibrium Model (2006), ed. D. Colander, Cambridge University Press, Cambridge.

Raport na temat petnego uczestnictwa Rzeczypospolitej Polskiej w trzecim etapie Unii Gospodarczej $i$ Walutowej (2009), NBP, Warszawa.

Reiter M. (2012), On the Welfare Costs of Unemployment Fluctuations, manuscript.

Rubaszek M. (2012), Mortgage Down-payment and Welfare in a Life-cycle Model, "Bank i Kredyt", 43(4).

Storesletten K., Telmer C. I., Yaron A. (2001), The Welfare Cost of Business Cycles Revisited: Finite Lives and Cyclical Variation in Idiosyncratic Risk, "European Economic Review", 45(7), http://dx.doi.org/10.1016/s0014-2921(00)00101-x.

Storesletten K., Telmer C. I., Yaron A. (2007), Asset Pricing with Idiosyncratic Risk and Overlapping Generations, "Review of Economic Dynamics", 10(4), http://dx.doi. org/10.1016/j.red.2007.02.004. 
Wróbel-Rotter R. (2013), Estymowane modele równowagi ogólnej i wektorowa autoregresja: model hybrydowy, "Bank i Kredyt", 44(5).

\section{Modele międzypokoleniowe $\mathrm{z}$ niejednorodnymi podmiotami i zagregowanym ryzykiem w badaniach makroekonomicznych}

(Streszczenie)

W pracy przedstawiono metodologię budowy międzypokoleniowych modeli DSGE z niejednorodnymi podmiotami i zagregowanym ryzykiem. Te stochastyczne modele makroekonomiczne pozwalają na uwzględnienie zróżnicowania konsumentów przede wszystkim ze względu na wiek oraz zasób majątku. Na przykładzie autorskiego modelu, który dodatkowo uwzględnia niejednorodność ze względu na status na rynku pracy oraz zdolności, pokazano sposób wyprowadzania kluczowych równań opisujących decyzje konsumpcyjne i inwestycyjne podmiotów. W pracy przedstawiono również najważniejsze algorytmy obliczeniowe stosowane do analiz omawianych modeli. Na końcu pokazano przykład zastosowania modelu do analizy kosztów wahań cyklicznych na rynku pracy w Polsce dla różnych grup konsumentów.

Słowa kluczowe: modele DSGE, modele międzypokoleniowe, niejednorodne podmioty, cykl koniunkturalny, algorytmy obliczeniowe. 